\title{
PBH ATIVOS S.A.: UMA INSTITUIÇÃO FINANCEIRA ÀS AVESSAS?
}

\section{PBH ATIVOS S.A .: A FINANCIAL INSTITUTION INSIDE OUT?}

\author{
Giovani Clark $^{1}$
Maria Jocelia Nogueira Lima
}

\section{RESUMO}

Com o aumento da criação de empresas controladas pela Administração Pública direta, sob a forma de sociedade anônima, em vários entes federados (São Paulo, Minas Gerais, Município de Belo Horizonte), com o fim precipuamente de ceder crédito de origem tributária ou não tributária, o artigo objetiva analisar tais cessões, especialmente modelo da PBH Ativos S.A. e logicamente a sua natureza perante a ordem jurídica. A pesquisa é eminentemente documental, apoiada na doutrina do Direito e na legislação. Possuindo, ainda, como principal referencial teórico o jurista Washington Peluso Albino de Souza, introdutor do Direito Econômico no Brasil.

Palavras-chave: Intervenção municipal no domínio econômico, Planejamento, Cessão de crédito tributário ou não, Antecipação receita, Pbh ativos s.a

\begin{abstract}
With the increase in the creation of companies controlled by direct public administration, in the form of corporation in various federal entities (Minas Gerais, São Paulo and Município de Belo Horizonte), with the primary purpose to cede right of tax credit origin or not tax, the article aims to analyze such assignments, especially model PBH Ativos S.A. and of course its nature before the law. The research is eminently documentary, based on the doctrine of law and legislation. Possessing also as the main theoretical jurist Washington Peluso Albino de Souza, introducer of Economic Law in Brazil.

Keywords/: Municipal intervention in the economic domain, Planning, Credit assignment, Anticipated revenue, $\mathrm{Pbh}$ ativos s.a

\footnotetext{
${ }^{1}$ Doutor em Direito Professor do Programa de Pós-Graduação stricto sensu em Direito da PUC Minas e da Graduação da Faculdade de Direito da UFMG, Universidade Federal de Minas Gerais - MG, Brasil: E-mail: indexlaw.ojs@hotmail.com

2 Especialista em Direito Tributário e em Direito Municipal pela PUC Minas, Procuradora Municipal de Belo Horizonte, Mestranda em Direito Público pela PUC Minas, Minas Gerais - MG, Brasil. E-mail: indexlaw.ojs@hotmail.com
} 


\section{INTRODUÇÃO}

O trabalho tem como foco a análise jurídica das cessões de crédito efetivadas entre a entidade pública da Administração Direta e as empresas de ativo criadas sob a forma de sociedade anônima que fazem parte da Administração Pública Indireta de tais entes federados, tendo como modelo para discussão a empresa vinculada ao Município de Belo Horizonte, PBH Ativos S.A., criada pela Lei n. 10.003/2010, em funcionamento desde 2011. Sociedade essa sob o controle acionário do dito Município, vinculada à Secretaria Municipal de Finanças, sob a forma de sociedade anônima, com sede e foro no Município de Belo Horizonte, a qual funcionará por tempo indeterminado.

Conforme o artigo $1^{\circ}$. da mencionada Lei Local, a PBH Ativos S.A. foi especialmente concebida para a cessão de direitos creditórios do Município à referida empresa, enquadrada dentro do víeis do Direito Econômico como uma intervenção direta estatal no domínio econômico.

A criação da PBH Ativos S.A., controlada pelo Município Belo Horizonte, destina-se precipuamente à captação de recursos para o poder local, através de operações de securitizações de créditos, em um momento de grave crise econômica e de consequente pressão sobre os chefes dos Executivos, de forma geral, na gestão das curtas receitas estatais na atual conjuntura econômico-financeira da nação.

Dessa forma, a PBH Ativos S.A. tem como objetivo social, dentre outros, titular, administrar e explorar economicamente ativos municipais; como também auxiliar o tesouro municipal na captação de recursos financeiros, podendo, para tanto, disponibilizar no mercado obrigações de emissão própria, receber, adquirir, alienar e dar em garantia os ativos, créditos, títulos e valores mobiliários da sociedade e, ainda, estruturar e implementar operações que visem à obtenção de recursos junto ao mercado de capitais, além de atuar em investimentos de infraestrutura e nos serviços públicos em geral, como nos projetos de concessões ou de parceria público privada, junto ao Município de Belo Horizonte.

Verifica-se que não somente no Município de Belo Horizonte há empresas controladas pela Administração Pública direta com referidos objetos sociais, também existe no próprio Estado de Minas Gerais, a Minas Gerais Participações S.A. MGI (a partir 
da faculdade concedida pelo art. 12, X, alínea “c” da Lei Delegada no. 179, de 01.01.2011 $\mathrm{e}$

integrante da Administração Direta conforme art. 14, parágrafo $1^{\circ}$, inciso $\mathrm{X}$ da Constituição do Estado de Minas Gerais), igualmente no Estado de São Paulo, cuja empresa foi autorizada através da Lei $\mathrm{n}^{\mathrm{o}}$ 13.723, de 29 de setembro de 2009, sob a denominação social de Companhia Paulista de Securitização (CPSEC), natureza jurídica de sociedade anônima de economia mista, controlada pelo Estado de São Paulo, constituída em 15 de outubro de 2009.

$\mathrm{Na}$ execução do seu objeto social, a PBH Ativos S.A., como as demais, tem efetivado cessões de direitos creditórios cuja origem é de créditos tributários ou não tributários, os quais devem ser utilizados na concretização do planejamento estatal (leis do plano plurianual, diretrizes orçamentárias e orçamento), e instituídos, ainda, por leis tributárias e cobrados mediante atividade administrativa plenamente vinculada.

Veja-se que a preocupação do chefe do executivo que sanciona a criação de tais empresas se mostra, teoricamente, em acolher os justos anseios da Administração Pública, visto que se por um lado a sua criação tem como foco principal a persecução de aumento de receita, através de implementação de operações que visem à obtenção de recursos, objetivando realizar suas funções constitucionais, junto ao mercado de capitais; de outro lado, não se pode esquecer que tais recursos têm origem e lastro em receitas auferidas através de atividade administrativa plenamente vinculada por imposição constitucional, sendo, portanto, inalienável e intransferível.

O presente trabalho visa, então, verificar se a criação dessas empresas, especialmente estudando o modelo da PBH Ativos S.A., estão dentro dos limites da ordem jurídica. A pesquisa investiga se as denominadas cessões de direitos creditórios ou operações com direitos creditórios, originadas de créditos tributários ou não tributários parcelados, realizadas por empresas como a PBH Ativos S.A., transformam-se, na verdade, em práticas limitadas às instituições financeiras, as quais devem ser, para tanto, previamente autorizadas pelo Banco Central do Brasil S.A., em conformidade à Lei 4.595/1964 (Dispõe sobre a Política e as Instituições Monetárias, Bancárias e Creditícias). 
Ademais, a pesquisa é eminentemente documental, apoiada na doutrina do Direito e na legislação. Possuindo, ainda, como principal referencial teórico o jurista Washington Peluso Albino de Souza, introdutor do Direito Econômico no Brasil.

\section{NEOLIBERALISMO DE REGULAÇÃO E O MODELO PESQUISADO DA PBH ATIVOS S.A.}

Tem-se que a matéria acerca da possibilidade de cessão de crédito ou efetivação de operações ditas de crédito em nossa Administração Pública ganhou força com os governos conservadores assumindo o poder estatal tanto na Grã Bretanha, com a denominada Dama de Ferro, como era chamada Margareth Thatcher, em 1979; e nos EUA com o governo Ronald Reagan, em 1980, ambos com as bandeiras da "eficiência" e do gerencialismo imediatamente aplicados após as suas posses. Depois outras nações começaram a efetivar reformas semelhantes, disseminando o neoliberalismo regulador (SOUZA, 2005; CLARK, 2008). Assim os serviços públicos passam por profundas transformações, perdendo os "traços burocráticos" e adquirem características próprias do gerenciamento privado e da eficiência do capital, com o direcionamento privatizante.

Na visão jurídica dos professores Clark, Corrêa, Nascimento (2013), tal onda denominada liberal-regulamentadora emerge na década de 80 do século XX e consolida-se em meio a um contexto histórico sui generis:

[...] por um lado, a afirmação de um projeto democrático e emanacipatório da afirmação de direitos sociais e econômicos cristalizados na Constituição Econômica e no extenso rol de direitos fundamentais e; por outro, a ascensão de um modelo de liberalização regulada da economia e, por conseguinte, a subordinação do projeto nacional aos desmandos de uma elite política e financeira internacional (Fundo Monetário Internacional, Banco Mundial, Estados do Norte) interessados em garantir a execução de seu projeto de exploração por meio da desregulamentacão de quaisquer barreiras ao livre fluxo do seu capital privado (CLARK, CORRỂA, NASCIMENTO, 2013, p. 268)

$\mathrm{Na}$ visão de Bresser Pereira (1998, p. 33), justificando a necessidade de mudanças no Estado para a introdução da Administração pública gerencial, após o

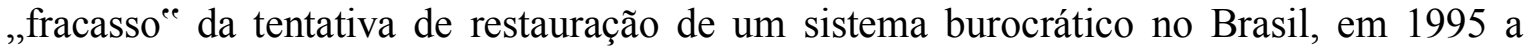
administração do Presidente Fernando Henrique Cardoso implementou a reforma gerencialista, onde a ideia geral era descentralizar, delegar autoridade, porém com maior 
especificidade, definindo claramente os setores onde o Estado age, as competências e as modalidades de administração adequada a cada setor, ou seja, a imposição do neoliberal regulador.

Ainda, segundo o referido autor, convencendo-se da necessidade de reforma na estrutural estatal, fulcrado no neoliberalismo, aponta que os Estados modernos atuam geralmente em quatro setores: núcleo estratégico (legislativos, executivos, judiciário e cúpulas de servidores civis), atividades exclusivas (envolvem o Poder do Estado, efetivação políticas públicas, funções tradicionais do Estado agências reguladoras), serviços não-exclusivos (educação, saúde, cultura e pesquisa) e a produção de bens e serviços para o mercado (empresas estatais) (PEREIRA, 1998, p. 33-34). A partir da reforma gerencialista, uma dos

pilares do neoliberal liberal, o Estado deveria limitar sua atuações aos dois primeiros setores, privatizando os outros dois.

Todavia, diferentemente do entendimento de Bresser Pereira, as políticas neoliberais de regulamentação, passaram, em verdade, a transferir serviços e atividades estatais à iniciativa privada, via desestatização (SOUZA, 2005 e CLARK., 2008), em prol da dilatação dos lucros:

Nos fim do século XX e no início do século XXI, as políticas neoliberais de regulamentação passaram a restringir a expansão e a mobilidade do capital. O novo ambiente mundial de fim da guerra fria, queda do socialismo real e de alta evolução tecnológica resultam em pressões por outras políticas econômicas ao gosto dos donos do capital. Os Estados nacionais passam a executar o neoliberalismo de regulação transferindo serviços e atividades á iniciativa privada (via privatização e desestatização) agora, atraentes ao capital, em face da "redução" dos ganhos com a indústria bélica da guerra fria e dos avanços científicos. Á tecnologia tornou lucrativo setores que anteriormente tinham baixa lucratividade, ou não tinham, e estavam nas mãos do Estado.

A partir da regulação, usada como único remédio salvador do mundo e protegida de grandes contestações pela mídia dos "donos do poder" (FAORO, 2000), o Estado passou a adotar uma nova técnica de ação na vida econômica, ou seja, o neoliberalismo de regulação. O poder estatal continuou a intervir indiretamente no domínio econômico, através das normas legais (leis, decretos, portaria), e intermediaria, via agências de regulação. Diferentemente das empresas estatais, as agencias não produzem bens nem prestam serviços à população, mas somente fiscaliza e regula o mercado ditando "comandos técnicos" de expansão, qualidade, indicadores de reajuste de preços, etc.

Todavia, é prudente frisar, que a técnica intervencionista de regulação permite a existência de algumas empresas estatais, em menor número, atuando no âmbito do mercado. Contudo, sem desempenhar o papel anterior e possuindo uma reduzida capacidade de ingerência na vida econômica (CLARK, 2008, p. 106) 
Essa onda neoliberal reguladora globalizada, replicada no Brasil, a partir de modelos trazidos da Grã Bretanha e Estados Unidos era uma preocupação permanente do saudoso mestre geógrafo, Professor Milton Santos (1999). Ele já ensinava criticamente nas comemorações dos 500 anos do Brasil:

O chamado internacional seria modelado pela economia e pela política, criando relações que acabam por supor pontos de vista seletivos e por impor ideias e ações que, na origem ou nos desdobramentos, são marcadas pelo pragmatismo. Pensou-se que o global seria abarcativo, democratizante. Mas na prática atual, ao contrário do que se podia sonhar, reduz ainda mais o escopo das trocas, abastarda as comparações e aprofunda a visão pragmática, na medida em que convoca todas as forças a buscar um único caminho. Já o universal, que é independente de realizações práticas imediatas, é encontrado na busca de uma generalidade significativa e representa não apenas as quantidades do mundo, mas as qualidades e valores. Por isso é abrangente de tudo e de todos, a despeito das hierarquias.

Quando o parâmetro é a universalidade, o pensamento começa e termina com o pensamento filosófico; quando, porém, trata-se de internacionalidade, internacionalismo ou globalismo, a centralidade vai à economia. $\mathrm{O}$ internacional e a modernidade sempre estiveram na raiz da nossa busca intelectual, ambos significando a Europa e, mais recentemente, também os Estados Unidos (SANTOS, 1999, pp. 49-50)

E continuando, esclarece, acentuando as consequências dessas cópias de modelos internacionais replicados em nossa Nação com percuciência:

\begin{abstract}
Esse caminhar acarretou pelo menos dois problemas. $\mathrm{O}$ primeiro, a partir da nossa construção via colonização, levava a limitar o pensamento na órbita de uma história que já havia sido feita por outros, como se a história nova fosse mera repetição ou herança obrigatória do passado alheio. O segundo problema vem de fato da mesma colonização, atribuindo ao ensino das ideias um certo caráter instrumental, na medida em que outras formas de pensar eram excluídas. No fundo, essa atitude acaba por produzir, perto ou longe, direta ou indiretamente, uma certa legitimação à instrumentalidade da economia na produção do pensamento social. (SANTOS, 1999, p. 50)
\end{abstract}

Apesar da onda globalizante com seu neoliberalismo regulador, nesses tempos de sua faceta de austeridade (NUNES, 2012) o Município de Belo Horizonte, como ente federado, tem competência para realizar o desenvolvimento autônomo local (art. 18 da $\mathrm{CR}$ ), intervindo nas atividades econômicas, sociais, tecnológicas, ambientais em seu território, de forma direta e indireta (SOUZA, 2005), conforme arts. 30 e 24 da constituição de 1988.

Assim sendo, os Municípios brasileiros devem e podem legislar em Direito Econômico articulando-se, dentre outros (arts. 170, 173, 174,175 da CR), os arts. 24, I e V com os art. 30, I e II da Constituição de 1988, agindo no domínio social e econômico a fim de efetivar dos comandos constitucionais 
possibilitadores de transformar a nossa realidade perversa (CLARK. 2013. p. 433)

O uso do dinheiro público e implementação das finanças municipais são também disciplinados pela Lei Complementar n. 101/2000, a Lei de Responsabilidade Fiscal (LRF), em conformidade ao artigo 163 do Texto Constitucional, inclusive no que refere-se a concessão de garantias pelas entidades públicas, emissão e resgate de títulos da dívida pública, fiscalização financeira da administração pública direta e indireta (Redação dada pela Emenda Constitucional n 40, de 2003), e operações de câmbio realizadas por órgãos e entidades da União, dos Estados, do Distrito Federal e dos Municípios.

No exercício da autonomia constitucional do poder local, o Município de Belo Horizonte promulgou a Lei 10.003/2010 criando uma empresa sob o seu controle acionário, vinculada à Secretaria Municipal de Finanças, sob a forma de sociedade anônima (PBH Ativos S.A.) com sede e foro no dito Município, a qual funcionará por tempo indeterminado (art. $1^{\circ}$.), cujo objeto social foi delimitado por seu artigo $2^{o}$ :

Art. $2^{\circ}$ - A sociedade terá como objeto social:

I - titular, administrar e explorar economicamente ativos municipais;

II - auxiliar o Tesouro municipal na captação de recursos financeiros, podendo, para tanto, colocar no mercado obrigações de emissão própria, receber, adquirir, alienar e dar em garantia os ativos, créditos, títulos e valores mobiliários da sociedade;

\footnotetext{
III - estruturar e implementar operações que visem à obtenção de recursos junto ao mercado de capitais;

(....)

$\mathrm{X}$ - participar de outras sociedades cujo objeto social seja compatível com suas finalidades;

XI - captar recursos ou estruturar operações que possibilitem a quitação, o refinanciamento, a redução do montante ou a diminuição dos encargos da dívida pública do Município;

XII - realizar quaisquer atividades que sirvam de instrumento para a conquista dos objetivos enunciados nos incisos anteriores.

Parágrafo único - A sociedade deverá agir somente no sentido de complementar as políticas públicas deliberadas pelos órgãos competentes, não podendo assumir outras funções e/ou responsabilidades da Administração Direta ou Indireta sem que para isso tenha sido contratada ou conveniada, procurando, sempre que possível, obter ganho econômico.
}

A par disso, não se pode perder de vista que a Lei de Responsabilidade Fiscal veda a cessão de créditos, equiparadas a operações de crédito, a título de antecipação de receita ou contribuição cujo fato gerador ainda não tenha ocorrido, constante do seu artigo 37, I. Aliás, uma das missões primordiais da PBH Ativos S.A., enquanto empresa 
municipal, praticando intervenção direta estatal no domínio econômico (SOUZA. 2005), é vender e comprar papéis no mercado financeiro, via bolsa de valores, dentre outras funções, influenciando e atuando nesse setor.

Ademais, tramitam no Congresso Nacional dois projetos de lei acerca de cessão de créditos tributários, sendo o primeiro para alteração da Lei Complementar $\mathrm{n}^{o} 5.172$, de 25.10.1966 (CTN); projeto $\mathrm{n}^{\circ} 181$ de 2015, que propõe a cessão de tais créditos; e o segundo, Projeto de Lei de n 3.777 de 2015, que dispõe sobre o procedimento legal apto a instrumentalizar a cessão creditícia através de licitação, cujo parecer da Procuradoria da Fazenda Nacional foi pela inconstitucionalidade de ambos os projetos (Parecer PGFNCDA no. 1505 de 2015 sobre os projetos de lei 181 e 3337 de 2015).

\section{A CESSÃO DE CRÉdITOS TRIBUTÁRIOS E NÃO TRIBUTÁRIOS A PBH ATIVOS S.A.}

A empresa municipal PBH Ativos S.A., criada inicialmente com capital social de $\mathrm{R} \$ 100.000,00$ (cem mil Reais) representado por dez mil ações ordinárias nominativas, sem valor nominal, integralizado pelo Município de Belo Horizonte em moeda corrente com recursos do Tesouro (art. $3^{\circ}$. Lei 10.003 de 2010), tem objetivo social reafirmado, conforme seu estatuto editado através do Decreto Municipal n ${ }^{\circ} 14.444 / 2011$ :

Art. $2^{\circ}$. A companhia tem como objeto social e realizará em nome próprio e por sua responsabilidade as seguintes atividades:

(...)..

c) estruturar e implementar operações que visem à obtenção de recursos junto ao mercado de capitais;(...).

1) captar recursos ou estruturar operações que possibilitem a quitação, o refinanciamento, a redução do montante ou a diminuição dos encargos da dívida pública do Município; (...).

Denota-se que, dentre os itens do objeto social, chamam a atenção dois especialmente: o concernente à captação de recursos ou estruturação de operações que possibilitem a quitação, o refinanciamento, a redução do montante ou a diminuição dos encargos da dívida pública do município (letra 1); como também estruturação e implementação de operações que visem à obtenção de recursos junto ao mercado de capitais (letra c). O referido Decreto municipal $\mathrm{n}^{o}$ 14.444/2011 dispõe ainda nos parágrafos do seu artigo $2^{\circ}$ : 
Parágrafo primeiro - A sociedade deverá agir somente no sentido de complementar as políticas públicas deliberadas pelos órgãos competentes, não podendo assumir outras funções e responsabilidades da Administração Direta ou Indireta sem que para isso tenha sido contratada ou conveniada, procurando, sempre que possível, obter ganho econômico.

Parágrafo segundo - A sociedade, para a consecução de seu objeto social, não receberá do Município de Belo Horizonte qualquer recurso financeiro para pagamento das despesas de pessoal ou de custeio em geral, vedada sua atuação como empresa dependente do Tesouro, nos termos da Lei Complementar federal n. 101, de 04 de maio de 2000.

Parágrafo terceiro - A sociedade poderá, a qualquer tempo, receber ativos para a realização do objeto social descrito no artigo $2^{\circ}$ deste Estatuto.

Veja-se, então, que PBH Ativos S.A. é considerada empresa „independente ${ }^{\text {ee }}$ da Administração Direta, conforme interpretação do parágrafo segundo, acima transcrito, do artigo $2^{\circ}$, da mesma lei. Ela também pode receber ativos do Município de Belo Horizonte como aporte de capital, conforme o artigo $4^{\circ}$. da Lei municipal $n .^{o}$ 10.003/2010, criadora da referida empresa, que dispõe:

Art. $4^{\circ}$ - Fica desde já autorizado ao Município o aumento de capital social da sociedade, a qualquer tempo, com contribuições em:

I - moeda corrente, desde que a soma das contribuições nessa forma não ultrapasse $0,1 \%$ (um décimo por cento) do orçamento municipal do ano; II - direitos creditórios de titularidade do Município, originários de créditos tributários e não tributários, devidamente constituídos, objeto de parcelamentos administrativos ou judiciais, observado o disposto no art. $7^{\circ}$ da Lei $n^{\circ} 7.932$, de 30 de dezembro de $1999^{1}$;

\footnotetext{
${ }^{1}$ AUTORIZA O EXECUTIVO A ASSOCIAR O MUNICÍPIO A OUTRAS ENTIDADES, VISANDO À CRIAÇÃO DE ASSOCIAÇÃO CIVIL COMUNITÁRIA E DÁ OUTRAS PROVIDÊNCIAS. Art. $1^{\circ}$ - Fica o Executivo autorizado a associar o Município a outras entidades, visando à criação de associação civil comunitária, sem fins lucrativos, com a finalidade de desenvolver ações buscando a recuperação da Bacia da Pampulha.

Art. $2^{\circ}$ - O Município participará da referida associação civil comunitária por meio de:

I - repasse de recursos financeiros;

II - integração aos órgãos de decisão;
}

III - direitos creditórios e direitos em geral, corporificados ou não em títulos, tais como os direitos correspondentes ao pagamento ao Município pela outorga de concessões e outros créditos e direitos que o Município ou as entidades integrantes da Administração Indireta venham a titular.

De fato, a PBH Ativos S.A. teve o seu aumento de capital via aporte financeiro do Município de Belo Horizonte, hoje perfazendo um total de $\mathrm{R} \$ 254.974 .385,83$ (duzentos e cinqüenta e quatro milhões, novecentos e setenta e quatro mil, trezentos e oitenta e cinco Reais e oitenta e três centavos), dividido em 29.920 .591 (vinte e nove milhões, novecentos e vinte mil, quinhentos e noventa e uma) ações ordinárias nominativas, sem valor nominal, isso ocorreu em razão da emissão de 200.000 mil ações ordinárias sem valor nominal em 
16.04.2012, ao preço de emissão de $\mathrm{R} \$ 10,00$ (dez Reais) e 29.685.591 ações ordinárias nominativas, sem valor nominal, em 29.05.2012, ao preço de $\mathrm{R} \$ 8,51$ (oito Reais e cinquenta e um centavos).

A questão alinha-se no sentido de que a empresa traz em seu objeto social a possibilidade de receber via cessão onerosa créditos tributários ou não tributários cedidos pelo ente público controlador, Município de Belo Horizonte, cessão esta que se mostra como

idêntica forma de empréstimos de forma geral, em troca de dinheiro recebido antecipadamente pelo administrador público, donde se vê que tais empréstimos no mercado de capitais serão pagos aos investidores com taxas atraentes obtidas pela receita da cobrança da dívida ativa, cujo titular continua o próprio controlador, como também se obriga financeiramente na demanda, sendo, pois, tais cessões verdadeiras operações de crédito, conforme a Lei de Responsabilidade Fiscal.

O propósito da cessão de crédito ou operação de crédito choca-se frontalmente com o conceito jurídico de tributo na concepção do art. $3^{\circ}$ do Código Tributário Nacional ${ }^{2}$, empecilho intransponível à tentadora transação, sendo ele (tributo) uma hipótese legal presumivelmente na pretensa obtenção de receita pública.

III - busca de parceiros nacionais e internacionais que facilitem a geração de renda. Parágrafo Único - O repasse financeiro de que trata o inciso I deste artigo terá o valor máximo de R\$ 200.000,00 (duzentos mil reais).

${ }^{2}$ Art. $3^{\circ}$. - Tributo é toda prestação pecuniária compulsória, em moeda ou cujo valor nela se possa exprimir, que não constitua sanção de ato ilícito, instituída em lei e cobrada mediante atividade administrativa plenamente vinculada.

Ora, se o tributo decorre da atividade administrativa plenamente vinculada da Administração Pública, a legislação local não pode simplesmente determinar a sua cessão a entidade privada para gerir, administrar ou mesmo lançar papéis no mercado de capitais, como debêntures originados de créditos tributários ou não tributários, como ocorreu.

Primeiramente, é inalienável e indisponível e, em sendo assim, não pode ser objeto de cessão a entidade privada como o foi. Deve ser usado pelo Município para 
realizar suas atribuições constitucionais de forma planejada (SOUZA, 2005; CLARK, 2001) e conforme a legislação.

Segundo, considerando que a empresa PBH Ativos S.A., em que pese se mostrar com a roupagem de pessoa jurídica de caráter „independente com recursos do Município de Belo Horizonte, como se vê da própria lei autorizativa, Lei municipal 10.003/2010, onde o artigo $3^{\circ}$ diz que os recursos para a referida empresa integralizar-se-ão através de recursos do tesouro.

Ocorre que em conformidade à Lei de Responsabilidade Fiscal (art. $2^{\circ}$ III), a empresa estatal que aporta recursos de capital com o ente controlador não pode ser designada empresa estatal independente. Assim sendo, a PBH Ativos S.A. não pode ser considerada em sua natureza jurídica como empresa independente.

Art. $2^{\circ}$ Para os efeitos desta Lei Complementar, entende-se como:

$(\ldots)$;

III - empresa estatal dependente: empresa controlada que receba do ente controlador recursos financeiros para pagamento de despesas com pessoal ou de custeio em geral ou de capital, excluídos, no último caso, aqueles provenientes de aumento de participação acionária.

Assim, a empresa citada, reafirmamos, aportou recursos do tesouro local para a integralização do capital social, não somente para o aumento do capital integralizado e, dessa forma, não há característica de empresa independente na PBH Ativos S.A. a lhe alicerçar, sendo-lhe proibida a realização de transações em mercado de capitais sem a devida autorização legislativa, especialmente quando tais transações originam-se em créditos tributários ou não tributários.

A cessão de crédito tributário do Município à $\mathrm{PBH}$ Ativos S.A. mostra-se inteiramente inconstitucional em vários aspectos, visto a inalienabilidade e indisponibilidade daquele, mesmo porque foi a própria Constituição Federal de 1988 quem quis que assim fosse, conforme diversos dispositivos do texto constitucional, incluindo o seu Capítulo I do Titulo VI (Da Tributação e do Orçamento).

Ademais, para se entender a inconstitucionalidade da cessão do crédito tributário ou não, que se mostra umbilicalmente vinculado à atividade desenvolvida pelos entes federados (União, Estados e Municípios), tem-se de revigorar os princípios que regem a repartição tributária, a criação dos tributos e a sua aplicação, enfim o próprio sistema tributário brasileiro. 
Desta feita, o princípio da igualdade (SILVA, 2009), conforme estampado no artigo 150, II da CR, prescreve que instituir tratamento desigual entre contribuintes que se encontrem em situação equivalente significa a sua quebra, sendo certo que, no caso de cessão de crédito tributário, o cidadão que optar pela negociação do seu crédito com a empresa cessionária recebedora do crédito do ente federado poderá ser aquinhoado com uma parcial remissão ou anistia, sem observância de uma lei autorizativa para tanto, com infringência literal a tal princípio, assim como do parágrafo $6^{\circ}$ do artigo 150 da CR. De igual forma, se houve a alienação (ou cessão) do crédito tributário para uma só pessoa está será quem negociará livremente com o contribuinte devedor, sem nenhuma observância aos comandos constitucionais para os tributos, caracterizando-se, novamente, a violação do artigo 150, II da CR, retirando o caráter objetivo que ensejam a aplicação dos ditames tributários, passando a vigorar a conveniência das partes, impossível juridicamente nessa tratativa.

Há, ainda, os princípios da repartição (SILVA, 2009) e vinculação de receita tributária que se mostra resguardada por várias normas constitucionais, como, exemplarmente, fixam os artigos 157, 158 e 159 e 212 da Constituição de 1988, que apontam o que cabe a cada ente da federação na arrecadação tributária, visto que sendo cedido o crédito tributário, por óbvio, não receberá a sua parcela respectiva o ente federado, visto que ao ser transferido referido crédito para uma empresa de caráter privado, mesmo sendo componente da Administração Indireta, não haverá a obediência à repartição tributária, trazendo empobrecimento aos entes federados por não receber os valores da arrecadação, inclusive com desvio de finalidade, razões pelas quais a Constituição Republicana pró́be em seu art. 167, IV a vinculação da receita de impostos. Portanto, não se pode vincular receita de impostos a nenhum órgão, ainda mais a empresa privada, sendo tal comportamento inconstitucional.

Aliada a todos esses impedimentos constitucionais que gravitam claramente pela inconstitucionalidade da cessão de crédito tributário, certo é que a competência para a sua cobrança é somente da pessoa jurídica de direito público, conforme artigo $7^{\circ}$, caput do CTN, através das suas respectivas procuradorias, não sendo delegáveis tais funções, mesmo porque são elas de caráter estruturante no Estado, como atividades essenciais ao funcionamento do 
Estado, exercidas por servidores de carreiras específicas, conforme inciso XXII do artigo 37 da CR.

De outro lado, tem-se que a cessão de crédito do poder local levado a termo pela PBH Ativos S.A., tendo como origem créditos tributários ou não tributários, se mostra como verdadeira e autêntica operação de crédito ou alienação de crédito realizada por entidade financeira, já que a empresa estudada pratica atos inerentes a assunção de compromisso financeiro, típica (confundindo) a verdadeira operação de crédito, vedada pelo art. 37, III da LRF. Portanto, a PBH Ativos S.A. é uma instituição financeira às avessas e de caráter "privilegiado", pois não precisa sequer de autorização de órgão competente para atuar.

Por outra banda, em uma posição jurídica oposta da tomada no presente artigo, verifica-se o memorando da Comissão de Valores Mobiliários $\left(\mathrm{CVM}^{3}\right)$, a pedido da empresa PBH Ativos S.A. para emissão de debêntures, originadas de cessão de créditos tributários ou não tributários, cujo entendimento foi pela desnecessidade de autorização do Senado Federal para tal operação, fulcrado na interpretação de ser supostamente empresa „independente e e controlada pelo Município de Belo Horizonte, optando pela legalidade da operação realiza pela empresa estudada. Vejamos:

Para: SGE MEMO/SRE/GER-2/ N. ${ }^{\circ}$ 07/2014

De: SRE Data: 7/3/2014

Assunto: Solicitação de anuência da CVM para emissão privada de debêntures simples Resolução CMN n. ${ }^{\circ}$ 2.391/97 - Processo CVM N. ${ }^{\circ}$ RJ-2014-1339 Senhor Superintendente Geral,

Trata-se de pedido de anuência desta Autarquia relativa à primeira emissão privada de debêntures simples, não conversíveis em ações, da espécie subordinada, em série única ("Debêntures Subordinadas"), da PBH ATIVOS S.A. ("Emissora" ou "PBH Ativos"), em atendimento ao disposto no art. 1. ${ }^{\circ}$ da Resolução CMN no 2.391/97.

Conforme expediente protocolado em 3/2/2014, a Emissora, sociedade por ações de economia mista e capital fechado, controlada pelo Município de Belo Horizonte, informa que emitirá privadamente até 10.000 (dez mil) debêntures subordinadas e não conversíveis em ações, que terão o valor nominal unitário de $\mathrm{R} \$ 100.000,00$ e série única.

A presente emissão foi aprovada por meio de Assembleia Geral Extraordinária e Reunião do Conselho de Administração, ambas realizadas em 12/12/2013, devidamente publicadas e arquivadas na JUCEMG. As condições e características da emissão foram aprovadas, em atendimento ao disposto no artigo 163, inciso III, da Lei n. ${ }^{\circ}$ 6.404/1976, em Reunião do Conselho Fiscal da Emissora realizada também em 12/12/2013.

A PBH Ativos informa também que poderá captar até R\$ 1 bilhão nessa operação privada, e o montante captado será totalmente subscrito e integralizado pelo Município de Belo Horizonte, por meio de cessão de direitos creditórios, constituídos por direitos de crédito autônomos para recebimento do fluxo de pagamentos decorrente de créditos tributários ou não tributários vencidos e parcelados, com duração limitada e definida ("Direitos de Crédito Autônomos"). 
3 Memorando constante do sítio eletrônico www.pbhativos.com.br visitado em dezembro de 2015 e 13.01.2016.

\begin{abstract}
As Debêntures Subordinadas serão integralmente utilizadas para realizar o pagamento do preço de aquisição dos Direitos de Crédito Autônomos cedidos à $\mathbf{P B H}$ Ativos. Nenhuma outra forma de captação de recursos será contratada para realizar o pagamento do preço de aquisição dos Direitos de Créditos Autônomos cedidos pelo Município à Emissora.

A data de emissão das Debêntures Subordinadas será 28/2/2014, e o prazo de vencimento será de 9 anos contados da data de emissão, de modo que o vencimento final das Debêntures Subordinadas ocorrerá em 28/2/2023. (...).

Nos termos aprovados na AGE de 12/12/2013, a oferta pública com esforços restritos das Debêntures com Garantia Real será de até R\$230.000.000,00, com a emissão de até 2.300 debêntures e prazo de 84 meses. Dos recursos líquidos obtidos pela $\mathrm{PBH}$ Ativos com essa emissão, 90\% serão utilizados para amortização programada extraordinária das Debêntures Subordinadas e o saldo destinado para obrigações corporativas diversas." (Grifos da subscritora).
\end{abstract}

Desta feita, as debêntures serão emitidas e utilizadas para a quitação, conforme informa o memorando acima da CVM, dos créditos tributários parcelados que foram antes cedidos a ela, caracterizando assim a operação de crédito, de acordo com o artigo 29, III da LRF, e proibido pelo art. 165, parágrafo $8^{\circ}$ da $\mathrm{CR}$, configurando antecipação de receita orçamentária não licenciada pelo texto constitucional.

Isso nada mais é do que uma verdadeira operação de crédito, vedada pela Lei de Responsabilidade Fiscal em seu artigo 29, III, visto se tratar de recebimento antecipado de valores provenientes da venda a termo de papeis, bens e serviços. O Prof. Harada (2016), em artigo recente, comentando sobre lei similar do Estado de São Paulo, lei no. 13.723 de 2009, autorizando as cessões de créditos tributários, aponta também sua ilegalidade e inconstitucionalidade. Ensina ele:

Criou-se, na verdade, nova modalidade de operação de crédito por Antecipação de Receita Orçamentária - ARO - não autorizada pela Constituição Federal (art. $165, \S 8^{\circ}$ ), nem prevista no art. 38 da LRF segundo o qual a ARO se destina unicamente para suprir a deficiência de caixa durante o exercício, só podendo ser realizada a partir do décimo dia do início do exercício para ser liquidada até o dia dez de dezembro de cada ano."

A lei sob comento permite a cedente receber no ato da cessão e de forma antecipada todo o montante do crédito tributário sob o regime de parcelamento. É uma espécie de antecipação de receita tributária sem previsão constitucional e sem regulamentação na LRF nos termos retrorreferidos. (HARADA, 2016)

Assim sendo, a PBH Ativos S.A., ao aplicar os seus „recursos financeiros ${ }^{\text {ee }}$ no mercado de capitais, cuja licença perquiriu junto à Comissão de Valores Mobiliários (CVM), conforme acima descrito, pratica atividades próprias das instituições financeiras, 
em conformidade à Lei 4.595/1964, sendo equiparadas àquelas, conforme seus arts. $17 \mathrm{e}$ 18 , parágrafo $1^{o}$

\section{CONSIDERAÇÕES FINAIS}

A PBH Ativos S.A., em conformidade a Lei 4.595/1964, está a exercer funções atinentes a instituição financeira, sem a devida autorização do Banco Central do Brasil, violando, ainda, comandos infraconstitucionais e dispositivos da Constituição brasileira de 1988, conforme exposto acima no trabalho.

A cessão de créditos tributários ou não tributários efetivada à empresa de ativos é inconstitucional, visto a sua indisponibilidade e a sua inalienabilidade, assim como a integral quitação de direitos creditórios originados de cessão dos ditos créditos tributários emitidos, através das debêntures da PBH Ativos S.A., caracterizando-se verdadeira operação de crédito, estando referida empresa a exercer atividades próprias de instituições financeiras, conforme a Lei no. 4.595/64.

Ademais, a criação dessa espécie de empresa, como a PBH Ativos S.A., típica intervenção direta estatal do domínio econômico, a fim de atuar no mercado financeiro, no intuito de negociar papéis ou ,produtos financeiros ${ }^{\mathrm{ee}}$, significa uma perigosa $\mathrm{e}$ inconstitucional entrada de empresa estatal na corrida da especulação mercadológica com recursos públicos, quiçá chega às raias do anarcocapitalismo, onde o Estado pode ser abolido e todas suas funções seriam assumidas pelo mercado.

As receitas do Estado, advinda de tributos, empréstimos e do seu patrimônio, são destinadas a implementar as diretivas do texto constitucional e, portanto, devem ser utilizados de forma planejada (legislação), seguindo os comandos e objetivos da nossa Lei Maior de 1988.

A violação a ordem jurídica brasileira, inclusive da Constituição da República, via manobras mirabolantes com os recursos públicos, sem qualquer controle popular, transparência e publicidade, não podem prosseguir, pois coloca em situação temerária a saúde financeira do Estado em um futuro bem próximo, já que empresas, coma a ora estudada, atuam em um setor de risco eminente e constante, onde a maioria esmagadora perdem dinheiro e uma pequena minoria ganham, já que somente o poder econômico privado estabelece as "regras" do cassino financeiro. 
A PBH Ativos S.A. mostra-se, em verdade, como uma instituição financeira às avessas, conforme as demais empresas estatais do mesmo gênero, criadas recentemente por Estados e outros Municípios brasileiros e não podem prosperar, devendo ser questionadas juridicamente. Assim sendo, não podem os Ministérios Públicos, a sociedade civil organizada ou não, o Judiciário, se renderem a mais um estratagema do neoliberalismo de regulação,

objetivando a expropriação de recursos públicos em prol do capital financeiro. Tais empresas

não foram criadas para ampliar as receitas públicas, no intuito de aplicá-las na concretude do

texto constitucional, mas apenas de transferir mais renda aos especuladores e de forma

bastante privilegiada.

\section{REFERÊNCIAS}

AVELÃS NUNES, Antônio José. A Crise atual do Capitalismo. Revista dos Tribunais, 2012.

BELO HORIZONTE - MG. Decreto Municipal no 14.444 de 2011. Belo Horizonte MG. Acessado em 29 de março de 2009: <https://leismunicipais.com.br/a/mg/b/belohorizonte/decreto/2011/1445/14444/decreto-n-14444-2011-aprova-o-estatuto-social-dapbh-ativos-sa>

BELO HORIZONTE - MG. Lei Municipal no 10.003 de 2010. Belo Horizonte - MG. Acessado 29 de março de 2016: <https://leismunicipais.com.br/a/mg/b/belohorizonte/lei-ordinaria/2010/1000/10003/lei-ordinaria-n-10003-2010-autoriza-a-criacaode-sociedade-sob-o-controle-acionario-do-municipio-de-belo-horizonte-e-estabeleceoutras-disposicoes-relativas-a-atuacao-da-entidade>

BELO HORIZONTE, Lei do Município de Belo Horizonte $\mathbf{n}^{\mathbf{0}} \mathbf{7 . 9 3 2}$, de 30 de dezembro de 1999, autoriza o executivo a associar o município a outras entidades, visando à criação de associação civil comunitária e dá outras providências. Acessado em 29 de março de 2016: <http://cm-belo-horizonte.jusbrasil.com.br/legislacao/237072/lei7932-99>

BERCOVICI, Gilberto. Constituição Econômica e Desenvolvimento: uma leitura a partir da Constituição de 1988. São Paulo: Malheiros, 2005.

BRASIL, Lei 4595, de 1964, dispõe sobre a Política e as Instituições Monetárias, Bancárias e Creditícias. Cria o Conselho Monetário Nacional e dá outras providências. 
Acessado em 29 de março de 2016:

<http://www.planalto.gov.br/ccivil_03/leis/L4595.htm>

BRASIL, Lei Complementar no. 5.172, de 25.10.1966, Código Tributário Nacional. Dispõe sobre o Sistema Tributário Nacional e institui normas gerais de direito tributário aplicáveis à União, Estados e Municípios. Acessado em 21 de março de 2016:

<http://www.planalto.gov.br/ccivil_03/leis/L5172.htm>

BRASIL, Memorando CVM sobre Solicitação de anuência da CVM para emissão privada de debêntures simples Resolução CMN n. ${ }^{\circ}$ 2.391/97 - Processo CVM N. ${ }^{\circ}$ RJ-2014-1339, site da www.pbhativos.gov.br, visitado em dezembro de 2015 e janeiro de 2016.

BRASIL, Projeto de Lei de $\mathbf{n}^{\mathbf{0}} \mathbf{3 . 7 7 7}$, de 2015, que dispõe sobre o procedimento legal apto a instrumentalizar a cessão de crédito através de licitação. Acessado em 18 de janeiro de 2016: < http://www2.camara.leg.br/proposicoesWeb>.

BRASIL, Projeto no 181, de 2015, que propõe a cessão de tais créditos, site visitado em 18 de janeiro de 2016: 〈http://www2.camara.leg.br/proposicoesWeb >

BRASIL. Constituição da República Federativa do Brasil. Brasília:

Centro de Documentação e Informação, Edições Câmara, 2012.

BRASIL. Lei de Responsabilidade Fiscal - Lei Complementar $n^{0} 101$ de 04 de maio de

2000. Brasília, Presidência da República, 2000. Acessado em: 21 de março de 2016:

<http://www.planalto.gov.br/ccivil_03/leis/LCP/Lcp101.htm>.

BRESSER PEREIRA, Luiz Carlos. Gestão do Setor Público: estratégia e estrutura para um novo Estado. Reforma do Estado e Administração Pública Gerencial. In: BRESSER PEREIRA, Luiz Carlos e SPINK, Peter Kevin. (Org.). 2 ${ }^{\mathrm{a}}$. Ed., Rio de Janeiro, Fundação Getúlio Vargas, 1998, p. 21-38.

CAMARGO, Ricardo Antônio Lucas. Curso Elementar de Direito Econômico. Porte Alegre: Núria Fabris Editora, 2014.

CASTRO, Sérgio Pessoa de Paula Castro, Parecer da AGE-MG sobre cessão de direitos creditórios do ESTADO DE MG à MGI - Acessado em 23 de março de 2016: 〈http://mgipart.com.br/projeto/mgi/arquivos/parecer-age.pdf>.

CLARK, Giovani. A ADI 1950: O Voto Aula do Direito Econômico. In: COSTA, José Augusto F; ANDRAADE, José Maria A. de; MATSUO, Alexandra M. H. Direito: Teoria e Experiência. Estudo em Homenagem a Eros Roberto Grau. Tomo I. São Paulo: Malheiros, 2013, p. 429-451. 
CLARK, Giovani. CORREAA, Leonardo Alves. NASCIMENTO, Samuel Pontes do. Ideologia Constitucional e Pluralismo Produtivo. Revista da Faculdade de Direito da Universidade Federal de Minas Gerais, v. Especial, 2013, p.265-300.

CLARK, Giovani. CORREAA, Leonardo Alves. NASCIMENTO, Samuel Pontes do (Org.). Direito Econômico em Debate. São Paulo: LTr, 2015.

CLARK, Giovani. O Município em face do Direito Econômico. Belo Horizonte, Del Rey, 2001.

CLARK, Giovani. Política Econômica e Estado. Revista da Faculdade de Direito da UFMG n 53. Belo Horizonte, jul/dez 2008, p. 103-117.

CORRÊA, RODRIGO SAMPAIO, Parecer PGFN-CDA no. 1505 de 2015 sobre os projetos de lei 181 e 3337 de 2015. Acessado em 18 de janeiro de 2016 <www.pgfn.fazenda.gov.br/arquivos.../Parecer_PGFN_CDA_1505.pdf>

GRAU, Eros Roberto. A Ordem Econômica na Constituição de 1988. 14 ed. São Paulo: Malheiros, 2010.

HARADA, Kiyoshi. Cessão de crédito tributário viola da Lei de Responsabilidade Fiscal.

In: Âmbito Jurídico, Rio Grande, XVI, n. 113, jun 2013. Disponível em:

<http://ambitojuridico.com.br/site/?n_link=revista_artigos_leitura\&artigo_id=13246\&revi sta_caderno=26>. Acesso em 18 de janeiro de 2016.

MIGUEL, Luis Felipe. Utopias do Pós-Socialismo - Esboços e projetos de reorganização radical da sociedade. Revista Brasileira de Ciências Sociais, vol. 21, no. 61, junho de 2006, p. 92-114.

SANTOS, Milton. O País Distorcido. Origem do texto: Especial para a Folha, Ed. MAIS, seção BRASIL, comemoração aos 500 anos. 1999.

SILVA, ANTÔNIO FERNANDO BARROS E. Parecer PGR na ADI no. 3786 sobre a inconstitucionalidade da resolução no. 33 de 2006 do Senado, publicado no site visitado em 14 de janeiro de 2016: <http://s.conjur.com.br/dl/parecer-pgr-adi-3786resolucao-3306.pdf>

SILVA, José Afonso da. Comentário Contextual à Constituição. $6^{\text {a }}$ edição. São Paulo: Malheiros, 2009.

SOUZA, Washington Peluso Albino de. CLARK, Giovani (Coord.). Direito Econômico e a Ação Estatal na Pós-Modernidade. São Paulo: LTr, 2011. 
SOUZA, Washington Peluso Albino de. CLARK, Giovani. Questões Polêmicas de Direito Econômico. São Paulo: LTr, 2008.

SOUZA, Washington Peluso Albino de. Primeiras Linhas de Direito Econômico. $6^{\mathrm{a}}$ edição.

São Paulo: LTr, 2005.

SOUZA, Washington Peluso Albino de. Teoria da Constituição Econômica.

Belo Horizonte: Del Rey, 2002. 